\title{
Penggunaan Aplikasi Microsoft Mathematics untuk Pengembangan Bahan Ajar matematika Siswa
}

\author{
Fitria Rizki1, Rany Widyastuti ${ }^{2}$ \\ ${ }^{1}$ Al-Kahfi. Jalan Karimun Jawa No.1 , Sukarame, Bandar Lampung 35133, Indonesia \\ ${ }^{2}$ Universitas Islam Negeri Raden Intan Lampung. Jalan Endro Suratmin, Sukarame, Bandar \\ Lampung 35133, Indonesia. \\ *Corresponding Author. E-mail: fitriarizkisattu@gmail.com
}

\begin{abstract}
Abstrak
Penelitian ini bertujuan untuk mengembangkan bahan ajar matematika berbantuan aplikasi Microsoft Mathematics pada siswa kelas XI. Adapun metode penelitian dan pengembangan yang digunakan adalah model 4D yang dikemukakan oleh Thiagarajan yang terdiri dari 4 tahapan yaitu: (1) define atau pendefinisian; (2) design atau perancangan; (3) develop atau pengembangan dan (4) disseminate atau penyebaran. Peneliti menggunakan teknik analisis data kualitatif dan kuantitatif. Penelitian ini menggunakan teknik pengumpulan data yaitu angket (kuisioner) berupa skala Likert untuk respon siswa. Hasil penelitian adalah media berupa bahan ajar matematika berbantuan aplikasi Microsoft Mathematics yang layak digunakan sebagai media pembelajaran untuk meningkatkan motivasi belajar siswa. Kelayakan media pembelajaran yang dihasilkan dari ahli materi dan ahli media adalah valid dan layak digunakan sebagai media pembelajaran. Respon siswa terhadap media pembelajaran yang diperoleh pada uji kelompok kecil yaitu sangat menarik dengan skor rata-rata sebesar 83\%. Pada uji lapangan besar diperoleh kriteria kemenarikan yaitu sangat menarik dengan skor rata-rata sebesar $87 \%$.
\end{abstract}

Kata Kunci : Microsoft Mathematics; Pengembangan Bahan Ajar Matematika

\section{Abstract}

This study aims to develop mathematics teaching materials assisted by Microsoft Mathematics applications in class XI students. The research and development method used is the $4 D$ model proposed by Thiagarajan which consists of 4 stages: (1) define; (2) design; (3) develop and (4) disseminate. Researchers used qualitative and quantitative data analysis techniques. This study uses data collection techniques namely questionnaire (questionnaire) in the form of a Likert scale for students responses. The results of the study are media in the form of mathematics teaching materials assisted by Microsoft Mathematics applications that are suitable to be used as learning media to improve student learning motivation. The feasibility of learning media produced from material experts and media experts is valid and is suitable for use as a learning medium. The response of students to the learning media obtained in the small group test is very interesting with an average score of $83 \%$. In field testing, the criteria for attractiveness are very interesting with an average score of $87 \%$.

Keywords : Microsoft Mathematics; Development of Mathematics Teaching Materials

\section{PENDAHULUAN}

Menurut (Arsyad, 2013) media adalah komponen sumber belajar atau wahana fisik yang mengandung materi instruksional dilingkungan siswa yang dapat merangsang siswa untuk belajar. Penggunaan media pada kegiatan $\begin{array}{lcc}\text { pembelajaran } & \text { bertujuan } & \text { untuk } \\ \text { mempermudah } & \text { guru } & \text { dalam }\end{array}$ menyampaikan materi. Salah satu bahan ajar yang sesuai dan tepat digunakan untuk siswa adalah dengan memodifikasi media pembelajaran dalam wahana yang menarik sehingga menumbuhkan rasa cinta terhadap pelajaran matematika 
(Kusuma, Nasution, \& Anggoro, 2018). Menurut (Prastowo, 2014) bahwa bahan ajar secara umum pada dasarnya merupakan segala bahan (baik informasi, alat, maupun teks) yang disusun secara sistematis yang menampilkan sosok utuh dari kompetensi yang akan dikuasai oleh siswa dan digunakan dalam proses pembelajaran dengan tujuan untuk perencaanan dan penelaahan implementasi pembelajaran. Terdapat banyak sekali media pembelajaran yang dapat digunakan dalam proses pembelajaran, salah satunya adalah bahan ajar berupa modul (Sari, Farida, \& Syazali, 2016).

Berdasarkan hasil observasi yang dilakukan di SMAN 7 Bandar Lampung terlihat bahwa bahan ajar yang digunakan hanya menggunakan buku paket dan LKS (Lembar Kerja Siswa). Bahan ajar tersebut yang digunakan dalam proses pembelajaran matematika belum menanamkan minat belajar siswa sehingga siswa mengalami kesulitan dalam memahami materi dan bahan ajar yang digunakan saat ini menyebabkan hasil belajar siswa belum maksimal. Buku paket dan LKS yang digunakan ini hanya berisi materi, contoh soal, dan soal-soal yang masih monoton dan tidak sesuai kebutuhan siswa artinya dalam buku paket dan LKS tidak memuat contoh media aplikasi untuk melihat benar atau salah dari hasil pekerjaan siswa. Selain itu juga pada buku paket dan LKS tersebut kurang terdapat contoh aplikasi nyata tentang matematika yang mendukung pada proses belajar siswa. Dengan hal ini, diperlukan bahan ajar yang dapat membantu peserta didik untuk menemukan dan mengalami sendiri secara langsung, yaitu bahan ajar berupa modul.

Modul adalah sebuah buku yang ditulis dengan tujuan agar peserta didik dapat belajar secara mandiri tanpa atau dengan bimbingan guru, sehingga modul berisi paling tidak tentang petunjuk belajar (petunjuk siswa atau guru), kompetensi yang akan dicapai, content atau isi materi, informasi pendukung, latihan, petunjuk kerja, dapat berupa Lembar Kerja (LK), evaluasi, balikan terhadap hasil evaluasi (Wulantina, 2013). Bahan ajar modul pembelajaran matematika berperan sebagai salah satu media pembelajaran yang seharusnya dibuat atau dirancang oleh guru mata pelajaran yang bersangkutan agar isi dan tujuan pembelajaran dapat tercapai.

Modul yang dipandang peneliti bisa memfasilitasi siswa untuk mengarahkan pola pikir siswa dan membangun kemandirian siswa dalam belajar adalah modul pembelajaran matematika berbantuan aplikasi Microsoft Mathematics. Microsoft Mathematics adalah program edukasi, yang dibuat untuk sistem operasi Microsoft Windows, yang membantu pengguna untuk menyelesaikan permasalahan matematika (Hernawati, 2009). Maka dengan adanya bahan ajar berupa modul matematika berbantuan aplikasi Microsoft Mathematics pada materi matriks kelas XI dapat meminimalisir kesulitan yang dialami siswa dan berisikan materi matematika secara rinci dan jelas agar dapat dipelajari dan mudah dipahami siswa.

Berdasarkan hasil penelitian terdahulu, telah dilakukan penelitian untuk mengembangkan bahan ajar matematika materi tentang garis dan sudut (Wulantina, 2013), persamaan kuadrat (Kesumayanti \& Putra, 2017), sistem persamaan linear (Suhendra, 2014), aritmatika sosial (Lismareni, Somakim, \& Kesumawati, 2015), integral (Ramdani, 2012), dan lingkaran (Malalina \& Kesumawati, 2013). Ada pula beberapa penelitian terdahulu yang mengembangkan bahan ajar pada jenjang perkuliahan seperti mata kuliah program linear (Rizki \& Linuhung, 2016; Zulmaulida \& Saputra, 2014) dan aljabar linear (Farida \& Suryadinata, 2016; 
Mahyudi, Ariani, \& Ramadianti, 2017). Perbedaan dengan produk yang dikembangkan peneliti yaitu peneliti megembangkan bahan ajar berbantuan aplikasi Microsoft Mathematics dengan materi yang akan berbeda.

Penelitian

memanfaatkan aplikasi Microsoft Mathematics dalam pembelajaran matematika (Arief, 2015; Ekawati, 2016; Hernawati, 2009; Oktaviyanthi, Safaah, \& Agus, 2017; Puspitorini, 2015; Rahayuningsih, 2018). Perbedaan dengan produk yang dikembangkan peneliti yaitu peneliti memanfaatkan aplikasi Microsoft Mathematics pada siswa kelas XI.

Berdasarkan beberapa penelitian terdahulu, peneliti menyimpulkan bahwa media pembelajaran berupa bahan ajar matematika berbantuan aplikasi Microsoft Mathematics memiliki potensi yang efektif untuk meningkatkan hasil belajar siswa. Maka diadakan penelitian yang bertujuan untuk mengembangkan bahan ajar matematika berbantuan aplikasi Microsoft Mathematics pada siswa kelas XI.

\section{METODE}

Penelitian ini menggunakan metode penelitian dan pengembangan (Research and Development). Research and Development merupakan suatu proses atau langkah-langkah untuk mengembangkan suatu produk baru atau menyempurnakan produk yang sudah ada yang dapat dipertanggung jawabkan. Model pengembangan pada penelitian ini menggunakan metode pengembangan perangkat pembelajaran model 4D. Model pengembangan perangkat pembelajaran model 4D yang disarankan oleh S. Thiagharajan, Dorothy S, Semmel, dan Melvyn I. Semmel (1974) terdiri dari 4 tahap pengembangan yaitu define, design, develop, disseminate (Kurniawan \& Nurlalela, 2013; Megawati, 2014; Patkur \& Wibowo, 2013; Wahyuningsih, T.,
Raharjo, T., \& Masithoh, 2013). Adapun tahapannya yaitu:

1. Tahap Pendefinisian (Define) syarat-syarat pengembangan bahan ajar matematika berbantuan aplikasi Microsoft Mathematics yang merupakan tujuan yang akan dicapai pada tahap penelitian ini.

2. Tahap Perancangan (Design)

Tahap ini dilakukan untuk merancang bahan ajar matematika berbantuan aplikasi Microsoft Mathematics pada siswa kelas XI.

3. Pengembangan (Develop)

Tahap ini dilakukan untuk menghasilkan bahan ajar berupa modul matematika berbantuan aplikasi Microsoft Mathematics pada siswa kelas XI.

4. Tahap Penyebaran (Disseminate)

Tahap terakhir pada penelitian ini adalah tahap penyebaran. Tahap disseminate dilakukan untuk mempromosikan produk pengembangan agar bisa diterima pengguna, baik individu, suatu kelompok atau sistem.

Dalam pengumpulan data, teknik yang digunakan pada penelitian ini adalah wawancara, angket skala likert dengan 4 jawaban dan yang digunakan dalam penilaian validasi ahli dapat dilihat pada Tabel 1.

Tabel 1. Skor Penilaian Validasi Ahli

\begin{tabular}{cc}
\hline Skor & Pilihan Jawaban Kelayakan \\
4 & Sangat Baik \\
3 & Baik \\
2 & Kurang Baik \\
1 & Sangat Kurang Baik \\
\hline
\end{tabular}

Skor penilaian total dalam analisa data dapat dilihat dalam Tabel 2. 
Desimal, 2 (1), 2019 - 4

Fitria Rizki, Rany Widyastuti

Tabel 2. Skor Angket Respon Siswa

\begin{tabular}{lc}
\multicolumn{1}{c}{ Kriteria } & Skor \\
Sangat Setuju(SS) & 5 \\
Setuju (S) & 4 \\
Cukup (C) & 3 \\
Tidak Setuju (TS) & 2 \\
Sangat Tidak Setuju (STS) & 1 \\
\hline
\end{tabular}

$\bar{x}=\frac{\sum_{i=1}^{n} x_{i}}{n}$

Dengan :

$\mathrm{P}=\frac{\text { Jumlah skor yang diperoleh }}{\text { Skor kriterium }} \times 100 \%$

Keterangan :

$\mathrm{P}=$ Persentase kelayakan

Dalam pengkonversian kelayakan produk dan kemenarikan produk dapat dilihat dalam Tabel 3.

Tabel 3. Range Persentase dan Kriteria Kualitatif Program

\begin{tabular}{lc}
\multicolumn{1}{c}{ Persentase (P) } & Kriteria \\
$\mathrm{P}>80 \%$ & Baik Sekali \\
$60 \%<\mathrm{P} \leq 80 \%$ & Baik \\
$40 \%<\mathrm{P} \leq 60 \%$ & Cukup \\
$20 \%<\mathrm{P} \leq 40 \%$ & Kurang \\
$\mathrm{P} \leq 20 \%$ & Sangat Kurang \\
\hline
\end{tabular}

\section{HASIL DAN PEMBAHASAN}

Hasil penelitian dan pengembangan ini adalah bahan ajar matematika berbantuan aplikasi Microsoft Mathematics. Tahapan yang digunakan dalam penelitian dan pengembangan ini adalah metode penelitian dan pengembangan 4D. Tahapan-tahapannya yaitu:

\section{Tahap Pendefinisian (Define)}

Tahap ini diperoleh informasi bahwa dalam proses belajar guru sudah menggunakan bahan ajar berupa buku paket dan LKS. Terkhusus untuk materi matriks guru belum menggunakan bahan ajar dengan bantuan aplikasi Microsoft Mathmatics.

2. Tahap Perancangan (design)
Bahan ajar yang akan dikembangkan yaitu bahan ajar matematika berupa modul berbantuan aplikasi Microsoft Mathematics untuk meningkatkan motivasi belajar siswa dan siswa tertarik dalam proses belajar mengajar pada materi matriks. Dalam tahap perancangan ini ada empat langkah meliputi penyusunan angket, pemilihan media, pemilihan format (format selection), rancangan awal (initial design)

3. Tahap Pengembangan (develop)

Tahap ini bahan ajar dibuat dengan berbantuan aplikasi Microsoft Mathematics. Selain itu pada tahap ini juga terdapat tahapan validasi ahli dan uji kelayakan produk. Setelah bahan ajar dibuat kemudian dilakukan penilaian oleh para ahli materi dan media. Setelah mendapat penilaian bahan ajar ini dinyatakan valid dan layak digunakan sebagai media pembelajaran. Untuk hasil validasi dapat dilihat dalam Tabel 4 dan Tabel 5.

Tabel 4. Hasil Rata-Rata Skor Validasi

\begin{tabular}{ccc}
\multicolumn{3}{c}{ Ahli Materi } \\
\hline $\begin{array}{c}\text { Rata-Rata } \\
\text { Skor }\end{array}$ & Kriteria & Keterangan \\
$83 \%$ & $\begin{array}{c}\text { Baik Sekali / } \\
\text { Valid }\end{array}$ & Tanpa Revisi \\
\hline
\end{tabular}

Tabel 5. Hasil Rata-Rata Skor Validasi Ahli Media

\begin{tabular}{ccc}
\hline $\begin{array}{c}\text { Rata-Rata } \\
\text { Skor }\end{array}$ & Kriteria & Keterangan \\
$96 \%$ & $\begin{array}{c}\text { Baik Sekali / } \\
\text { Valid }\end{array}$ & Tanpa Revisi \\
& & \\
\hline
\end{tabular}

Setelah desain produk divalidasi melalui penilaian ahli materi, dan ahli media, peneliti melakukan revisi terhadap desain produk yang dikembangkan berdasarkan masukanmasukan ahli tersebut. Selanjutnya setelah dilakukan perbaikan desain dan dinyatakan valid maka dilakukan uji coba produk. Hasil uji coba terkait kemenarikan dilakukan melalui dua tahapan yaitu uji kelompok kecil dan uji 
coba lapangan. Uji coba kelompok kecil dilaksanakan dalam kelompok kecil yaitu melibatkan 12 siswa dan uji coba lapangan melibatkan 30 siswa yang dipilih secara heterogen berdasarkan kemampuan dikelas dan jenis kelamin. Uji coba tersebut dilakukan dengan memberikan bahan ajar matematika berupa modul kepada peserta didik untuk mengetahui respon peserta didik terhadap kemenarikan modul. Berikut ini hasil uji coba kelompok kecil dan uji coba lapangan dapat dilihat dalam Tabel 6.

Tabel 6. Hasil Rata-rata Angket Respon Siswa

\begin{tabular}{ccc}
\hline \multicolumn{2}{c}{ Skor Rata-Rata } & Kriteria \\
Skala Kecil & $83 \%$ & Baik Sekali \\
Skala Besar & $87 \%$ & Baik Sekali \\
\hline
\end{tabular}

Tabel 6 menunjukan hasil dari uji coba skala kecil dengan perolehan angka 83\% dengan kriteria "Baik Sekali". Pada uji coba skala besar dengan perolehan angka 87\% dengan kriteria "Baik Sekali". Kriteria ini menunjukan bahwa media pembelajaran berupa bahan ajar matematika yang dikembangkan layak untuk digunakan dan terbukti valid.

Selain itu, setelah melakukan uji coba kelompok kecil dan uji coba lapangan peneliti melakukan wawancara terhadap siswa dan guru mengenai produk yang di uji cobakan. Hasil respon siswa terhadap bahan ajar matematika berbantuan aplikasi Microsoft Mathematics ini siswa sangat antusias dan mengatakan bahwa bahan ajar ini sangat menarik untuk digunakan sebagai media pembelajaran. Setelah dilakukan wawancara dengan siswa kemudian peneliti juga melakukan wawancara kepada guru matematika di SMAN 7 Bandar Lampung, respon guru terhadap bahan ajar ini mengatakan bahwa bahan ajar ini sangat menarik dan dapat digunakan oleh guru dan siswa sebagai media pembelajaran serta diharapkan mampu meminimalisir kesulitan yang dialami siswa dan berisikan materi matematika yang jelas agar siswa dapat mudah memahami materi tersebut serta dapat meningkatkan motivasi belajar siswa.

Beberapa penelitian yang relevan pada penelitian ini yaitu (1) Penelitian oleh (Ekawati, 2016) menunjukan bahwa dalam penggunaan software Microsoft Mathematics peserta didik dapat memahami materi matematika dengan baik dan dapat meningkatkan kemampuan daya berfikir logis. (2) Penelitian oleh (Arief, 2015) yang mengembangkan media pembelajaran matematika dengan aplikasi Microsoft Mathematics mendapat hasil bahwa para peserta belajar bersikap sangat puas terhadap penggunaan aplikasi Microsoft Mathematics sehingga pembelajaran komputer mempunyai interaksi antara peserta belajar dengan program aplikasi Microsoft Mathematics sebagai media belajar berbantuan komputer yang dapat membantu peserta belajar. (3) Penelitian oleh (Oktaviyanthi \& Supriani, 2014) menunjukan bahwa dalam proses pembelajaran berbantuan Microsoft Mathematics dapat meningkatkan hasil belajar peserta didik dan dapat mempresentasikan solusi dan memberikan umpan balik kepada pendidik dalam proses pembelajaran.

Berdasarkan penelitian terdahulu, keterbaruan dalam penelitian ini terletak pada pengembangan bahan ajar matematika berbantuan aplikasi Microsoft Mathematics pada materi matriks untuk kelas XI SMA/MA. Dalam hal ini dapat disimpulkan bahwa bahan ajar matematika berbantuan aplikasi Microsoft Mathematics sangat menarik dan layak untuk digunakan sebagai salah satu media pembelajaran matematika bagi siswa dan guru dalam proses pembelajaran matematika pada materi matriks untuk kelas XI SMA/MA. 
Desimal, 2 (1), 2019 - 6

Fitria Rizki, Rany Widyastuti

\section{SIMPULAN DAN SARAN}

Kesimpulan yang diperoleh dari penelitian dan pengembangan ini adalah bahan ajar matematika berbantuan aplikasi Microsoft Mathematics layak digunakan dengan nilai rata-rata dari ahli materi sebesar $83 \%$ dan nilai rata-rata dari ahli media sebesar 96\%. Selain itu respon siswa yang dilakukan sebanyak dua kali yaitu uji coba kelompok kecil dan uji coba lapangan dan masuk pada kategori sangat menarik dengan rata-rata skor pada uji coba kelompok kecil sebesar $83 \%$ dan uji coba lapangan sebesar $87 \%$.

Berdasarkan kesimpulan di atas bahwa bahan ajar matematika berbantuan aplikasi Microsoft Mathematics pada siswa kelas XI dalam kriteria "Baik Sekali" dan layak untuk digunakan. Penulis menyarankan kepada peneliti lain agar dapat mengembangkan bahan ajar matematika berbantuan aplikasi Microsoft Mathematics pada materi yang lainnya.

\section{DAFTAR PUSTAKA}

Arief, M. (2015). Pengembangan Model dan Media Pembelajaran Matematika Ekonomi dan Bisnis dengan Aplikasi Microsoft Mathematics. Jurnal Pendidikan Bisnis Dan Manajemen, 1(2), 79-88.

Arsyad, A. (2013). Media Pembelajaran. Jakarta: Raja Grafindo Persada.

Ekawati, A. (2016). Penggunaan Software Geogebra dan Microsoft Mathematic dalam Pembelaran Matematika. Math Didactic: Jurnal Pendidikan Matematika, 2(3), 148-153.

Farida, N., \& Suryadinata, N. (2016). Pengembangan Bahan Ajar Mata Kuliah Aljabar Linear Berbasis Open Ended. Aksioma, 5(2), 145-151.

Hernawati, K. (2009). Pembelajaran Aljabar Linier dengan Perangkat Lunak Bantu Microsoft Math. In Seminar Nasional Aljabar,
Pengajaran Dan Terapannya (Pp. 219-232).

Kesumayanti, N., \& Putra, R. W. Y. (2017). Pengembangan Bahan Ajar Materi Persamaan Kuadrat Berbantuan Rumus Cepat. Jes-Mat, 3(2), 125-138. Kurniawan, A. D., \& Nurlalela, L. (2013). Pengembangan Buku Siswa untuk Meningkatkan Proses dan Hasil Belajar Kompetensi Dasar Cornflake Cookies pada Siswa Tunagrahita SMA-LB Negeri Gedangan, Sidoarjo. E-Journal Boga, 2(1), 6-17.

Kusuma, R. D. F. D., Nasution, S. P., \& Anggoro, B. S. (2018). Multimedia Pembelajaran Matematika Interaktif Berbasis Komputer. Desimal: Jurnal Matematika, 1(2), 191-199.

Lismareni, N., Somakim, \& Kesumawati, N. (2015). Pengembangan Bahan Ajar Materi Aritmetika Sosial Menggunakan Konteks Bahan Bakar Minyak dengan Pendekatan Pendidikan Matematika Realistik Indonesia di SMP. Jurnal Pendidikan Matematika, 9(1), 48-58.

Mahyudi, Ariani, N. M., \& Ramadianti, W. (2017). Desain Bahan Ajar Mata Kuliah Aljabar Linear untuk Mengembangkan Kemampuan Berpikir Kreatif Matematis. Jurnal Pendidikan Matematika, 2(1), 1-14.

Malalina, \& Kesumawati, N. (2013). Pengembangan Bahan Ajar Interaktif Berbasis Komputer Pokok Bahasan Lingkaran untuk Kelas VIII Sekolah Menengah Pertama. Jurnal Pendidikan Matematika, 7(2), 55-70. Megawati, C. (2014). Pengembangan Media Pembelajaran BIPA Tingkat Menengah Melalui E-Book Interaktif di Programincountry Universitas Negeri Malang Tahun 2014. NOSI, 2(1), 62-70.

Patkur, M., \& Wibowo, T. W. (2013). Pengembangan Modul Pembelajaran Autocad untuk Meningkatkan Efektivitas Pembelajaran Siswa Kelas $\mathrm{X}$ TPM di SMKN 1 Sidoarjo. JPTM, 
Desimal, 2 (1), 2019 - 7

Fitria Rizki, Rany Widyastuti

1(3), 86-96.

Oktaviyanthi, R., Safaah, E., \& Agus, R. N. (2017). Keterampilan Guru Matematika dalam Menyusun Bahan Ajar Berbantuan Mathematics Education. Jurnal Pengabdian Masyarakat Wikrama Parahita, 1(1), 19-24.

Oktaviyanthi, R., \& Supriani, Y. (2014). Pembelajaran Kalkulus Berbantuan Microsoft Mathematics. Admathedu, 4(2), 173-190.

Prastowo, A. (2014). Pengembangan Bahan Ajar Tematik. Jakarta: Kencana.

Puspitorini, A. (2015). Meningkatkan Pemahaman Mahasiswa dengan Penggunaan Microsoft Mathematics sebagai Media Pembelajaran. SIgma, 1(1), 13-17.

Rahayuningsih, S. (2018). Pemanfaatan Software Microsoft Mathematics dalam Pembelajaran Matriks. Majamath, 1(1), 74-83.

Ramdani, Y. (2012). Pengembangan Instrumen dan Bahan Ajar untuk Meningkatkan Kemampuan Komunikasi, Penalaran, dan Koneksi Matematis dalam Konsep Integral. Jurnal Penelitian Pendidikan, 13(1), 44-52.

Rizki, S., \& Linuhung, N. (2016).
Pengembangan Bahan Ajar Program Linear Berbasis Kontekstual dan ICT. Aksioma, 5(2), 137-144.

Sari, F. K., Farida, \& Syazali, M. (2016). Pengembangan Media Pembelajaran (Modul) Berbantuan Geogebra Pokok Bahasan Turunan. Al-Jabar: Jurnal Pendidikan Matematika, 7(2), 135151.

Suhendra, S. (2014). Pengembangan Bahan Ajar Sistem Persamaan Linear dengan Microsoft Excel di Sekolah Menengah Atas. Jurnal Pendidikan Matematika, 7(2), 56-70.

Wahyuningsih, T., Raharjo, T., \& Masithoh, D. F. (2013). Pembuatan Instrumen Tes Diagnostik Fisika SMA Kelas XI. Jurnal Pendidikan Fisika, 1(1), 111117.

Wulantina, E. (2013). Pengembangan Bahan Ajar Matematika yang Terintegrasi Nilai-Nilai Keislaman pada Materi Garis dan Sudut. In Seminar Nasional Matematika dan Pendidikan Matematika UIN Raden Intan Lampung (pp. 367-373).

Zulmaulida, R., \& Saputra, E. (2014). Pengembangan Bahan Ajar Program Linear Berbantuan Lindo Software. Infinity: Jurnal Ilmiah Program Studi Matematika STKIP Siliwangi Bandung, 3(2), 189-216. 